\title{
In vitro inhibition of influenza virus infection by a crude extract from Isatis indigotica root resulting in the prevention of viral attachment
}

\author{
ZIFENG YANG $^{1,2^{*}}$, YUTAO WANG $^{1 *}$, SHAN ZHONG $^{3}$, SUISHAN ZHAO $^{1}$, XIANGTENG ZENG $^{3}$, \\ ZIYAO MO ${ }^{1}$, SHENG QIN ${ }^{1}$, WENDA GUAN ${ }^{1}$, CHUYUAN LI $^{4}$ and NANSHAN ZHONG ${ }^{1}$ \\ ${ }^{1}$ Clinical Virology Division, State Key Laboratory of Respiratory Diseases (Guangzhou Medical University), \\ The First Affiliated Hospital of Guangzhou Medical College, Guangzhou; ${ }^{2}$ Macau University of Science and Technology, \\ Taipa, Macau S.A.R.; ${ }^{3}$ Guangzhou Institute of Pharmaceutical Industry, Guangzhou; ${ }^{4}$ Hutchison \\ Whampoa Guangzhou Baiyunshan Chinese Medicine Co., Guangzhou, P.R. China
}

Received July 8, 2011; Accepted October 14, 2011

DOI: $10.3892 / \mathrm{mmr} .2011 .709$

\begin{abstract}
Isatis indigotica root (IIR) has been widely used as a Chinese medicinal herb to treat regular seasonal influenza over the long history of traditional Chinese medicinal practice. However, its inhibitory activities against influenza virus infections along with the associated mechanisms have not been investigated comprehensively. In this study, the chemical nature, mode of action and in vitro anti-influenza activities of a crude extract (G2) of IIR were characterized. The extract was found to inhibit different subtypes of human or avian influenza viruses at various magnitudes of activity $\left(\mathrm{IC}_{50} 0.39-4.3 \mathrm{mg} / \mathrm{ml}\right)$ in vitro, including $\mathrm{A} / \mathrm{PR} / 8 / 34$ (H1N1), A/FM/1/47 (H1N1), A/Aichi/2/68 (H3N2), seasonal influenza (A/Guangzhou/ GIRD/02/09 H1N1, B/Guangzhou/GIRD/08/09), novel swineoriginating influenza (A/Guangzhou/GIRD/07/09, H1N1), A/ Duck/Guangdong/09 (H6N2), A/Duck/Guangdong/94 (H7N3) and A/Chicken/Guangdong/96 (H9N2), while G2 was inactive against respiratory syncytial virus (RSV), adenovirus 3 (ADV3), parainfluenza virus 3 (PIV3) and enterovirus 71 (EV71). An apparent virus titer reduction was detected when the influenza viruses were pretreated with G2, and it was also shown that G2 exhibited inhibitory effects on influenza virus hemagglutination. In addition, G2 played a role in the early stages of infection, which did not easily result in the emergence of virus drug resistance. Thus, G2 may affect the attachment of influenza virus by interfering with the viral
\end{abstract}

Correspondence to: Professor Nanshan Zhong, State Key Laboratory of Respiratory Diseases (Guangzhou Medical College), First Affiliated Hospital of Guangzhou Medical College, 151 YanJiang Road, Guangzhou 510120, P.R. China

E-mail: nanshan@vip.163.com

*Contributed equally

Key words: influenza virus, Isatis indigotica root, crude extract, in vitro particles, thereby preventing the binding of influenza virus to the host cell surface.

\section{Introduction}

Influenza, an acute respiratory infection caused by the influenza virus, is one of the public concerns to human health, and as a result the World Health Organization (WHO) monitors the appearance of viruses $(1,2)$. The emergence of a novel influenza A (H1N1) virus from Mexico in March 2009 resulted in a global outbreak, which prompted the WHO to raise the influenza pandemic alert to its highest level (3).

Currently, the main antiviral drugs approved for the treatment and prevention of the influenza virus are oseltamivir or zanamivir, targeting neuraminidase, and the adamantane derivative targeting the M2 protein (4). However, recent observation has shown a significant increase in antiviral drugresistance among influenza viruses worldwide, especially the M2 inhibitor(4). Since the outbreak of human infection with highly pathogenic avian influenza viruses in 1997, the extremely aggressive avian influenza virus (H5N1) has been considered to increase the likelihood of a human influenza pandemic (5). A novel swine-originating pandemic influenza virus is also now a major concern. For these reasons, discovery of novel therapeutic agents against influenza viruses are crucial and urgently required.

Isatis indigotica root (IIR, Radix isatidis), also known as Ban-Lan-Gen, which belongs to the family Cruciferae, is widely distributed in northern and central China. This medicinal plant has been traditionally used for the treatment of influenza, viral pneumonia, mumps, pharyngitis and hepatitis (6). Although there was no definite experiment and clinical evidence, IIR was used to treat patients in China when the severe acute respiratory syndrome (SARS) broke out in 2003.

Since the late 20th century, more and more compounds were found in IIR, including alkaloids (7-11), sucrose (9), organic acids $(7,9)$ and glycosides $(9,12)$. However, the majority of these compounds have not shown potent antiviral activities until recently, especially the antiviral monomers. Indirubin has been 
shown to have potent anti-influenza virus activity by inhibition of RANTES (also known as CCL5) expression (13). Yamada previously reported a glycoprotein from $R$. isatidis that showed useful antiviral activities in the therapy and prevention of virus infection in vitro and in vivo (14). He also reported that the polysaccharide from $R$. isatidis displayed production activity for an antibody as well as the adjuvant activity of a vaccine.

Nevertheless, to the best of our knowledge, the actual antiviral substance and mechanisms are yet to be elucidated. In the present study, the chemical nature, mode of action and in vitro anti-influenza activities of a crude extract, G2, from IIR were described.

\section{Materials and methods}

Plant materials, cells and viruses. The IIR, cultivated in Fuyang (GAP Farms, An-Hui Province, China) was obtained from Hutchison Whampoa Guangzhou Baiyunshan Chinese Medicine Co., Ltd. It was authenticated by Professor Y.E. Huagu at the Chinese Medicine Research Institute.

Madin-Darby canine kidney (MDCK), HEp-2 and LLC-MK2 cells were purchased from the American Tissue Culture Collection (ATCC; Manassas, VA, USA). Influenza viruses, $\mathrm{A} / \mathrm{PR} / 8 / 34 \quad(\mathrm{H} 1 \mathrm{~N} 1), \mathrm{A} / \mathrm{FM} / 1 / 47 \quad$ (H1N1), A/ Aichi/2/68 (H3N2), parainfluenza virus 3 (PIV-3) and respiratory syncytial virus (RSV; long strain), were purchased from ATCC, and seasonal influenza viruses, A/Guangzhou/ GIRD02/09 (H1N1), B/Guangzhou/GIRD/08/09, novel swine influenza virus (A/Guangzhou/GIRD/07/09, H1N1, GenBank Accession no. HM014332.1), adenovirus type 3 (ADV3) and enterovirus 71 (EV71), were isolated from routine clinical specimens. Avian influenza strains of H6N2 (A/Duck/ Guangdong/09), H7N3 (A/Duck/Guangdong/94), H9N2 (A/Chicken/Guangdong/96) were a kind gift from Dr Chen Jianxin. The influenza viruses were propagated and passaged in MDCK cells. HEp-2 cells were used as the host for RSV and ADV3. LLC-MK2 cells were used for culturing PIV-3. Vero cells were used to culture the EV71 virus. All of the cells were grown in Dulbecco's modified Eagle's medium (DMEM) with $10 \%$ heat-inactivated fetal calf serum (FCS).

Extraction and purification of $G 2$. The roots (960 g), ground into powder, were extracted twice with distilled water at $95-100^{\circ} \mathrm{C}$, each time for $2 \mathrm{~h}$, and then filtered. All of the water extracts were concentrated by reducing the pressure, and were precipitated with $60 \%$ ethanol sequentially at $4^{\circ} \mathrm{C}$ overnight. The supernatant was purified with a column of macroreticular resin (R 25 mm x H 90 mm, Beijing H\&E Co., Ltd) and eluted with distilled water (I), $20 \%$ ethanol (II), $40 \%$ ethanol (III), $60 \%$ ethanol (IV), $80 \%$ ethanol (V) and $100 \%$ ethanol (VI) in sequence at a flow rate of $5 \mathrm{ml} / \mathrm{min}$, and then we obtained six fractions (part I-VI) (Fig. 1A). The results of the cytopathic effect (CPE) activity assay showed that part I showed prominent activity. Part I was then deproteinized with Sevag reagent $\left(\mathrm{CHCl}_{3} / n-\mathrm{BuOH}, \mathrm{v} / \mathrm{v}=4: 1\right)$, decolorized with $5 \%(\mathrm{~g} / \mathrm{ml})$ activated carbon, dialyzed and lyophilized to get four brown fraction mixtures: G1 (<3,500 Da), G2 (3,500-7,000 Da), G3 (7,000-14,000 Da) and G4 (>1,4000 Da) (Fig. 1B). The activity of G1-4 was assessed using a plaque assay and the results showed that $\mathrm{G} 2$ had marked activity.
Characterization of $G 2$. The total sugar contents of G2 was determined using the phenol-sulfuric acid method, with glucose as the standard solution (15); the total protein contents were measured by the Bradford method, with bovine serum albumin as the standard (16).

Cytotoxicity assay. MDCK cells were left untreated or treated with the indicated amounts of G2. Cell viability was measured with the MTT assay. Briefly, cells were treated with $5 \mathrm{mg} / \mathrm{ml}$ thiazole blue tetrazolium bromide in phosphate-buffered saline (PBS) and incubated for $3 \mathrm{~h}$ at $37^{\circ} \mathrm{C}$. The reaction product was dissolved in DMSO and cells were further incubated for $20 \mathrm{~min}$ at $37^{\circ} \mathrm{C}$. The absorbance was measured in a microplate reader at $570 \mathrm{~nm}(17)$.

Viral infections. For infection, cells were washed with $\mathrm{PBS}$, incubated with the virus diluted in serum-free MEM containing $100 \mathrm{U} / \mathrm{ml}$ penicillin and $0.1 \mathrm{mg} / \mathrm{ml}$ streptomycin for $1.5 \mathrm{~h}$ at $34^{\circ} \mathrm{C}$ at the indicated multiplicities of infection (MOI). The inoculum was aspirated and cells were incubated with MEM supplemented with $2 \mu \mathrm{g} / \mathrm{ml}$ TPCK-trypsin.

Viral production assay. MDCK cells $\left(0.8-1.0 \times 10^{5}\right)$ were seeded into each well of 12 -well plastic plates and cultured at $37^{\circ} \mathrm{C}$ for 24-48 $\mathrm{h}$. For the anti-influenza activity assay and identification of the virus life cycle that was affected, cells were treated with G2 using three different protocols (18-20) (Fig. 2). First, prior to viral adsorption, the cells were pre-incubated with $\mathrm{G} 2$ for $2 \mathrm{~h}$ at $34^{\circ} \mathrm{C}$. Then the treated cells were washed and inoculated with the virus $(\mathrm{MOI}=0.01)$ for $2 \mathrm{~h}$ in the absence of $\mathrm{G} 2$ and further cultured for 48-72 h. Second, cells were inoculated with the virus at $34^{\circ} \mathrm{C}$ for $2 \mathrm{~h}$, and the infected cells were then washed and cultured for 48-72 $\mathrm{h}$ in the presence of G2. Third, diluted G2 was mixed with the virus and incubated at $37^{\circ} \mathrm{C}$ for $30 \mathrm{~min}$, and the infected cells were further cultured for 48-72 h. The amount of progeny virus was determined using a plaque assay and staining with crystal violet.

Hemagglutination inhibition assay. Influenza viruses are characterized by their ability to agglutinate erythrocytes. In the hemagglutination inhibition assay, $25 \mu \mathrm{l}$ of various concentrations of G2 was pre-incubated with $25 \mu 1$ virus stock and then mixed with $50 \mu 1$ of $0.5 \%$ guinea pig erythrocytes in a 96-well plate. The plate was incubated for $2 \mathrm{~h}$ at $4^{\circ} \mathrm{C}$ and observed for hemagglutination.

Addition of G2. MDCK cells in 24-well plates were prepared, then infected with virus $(\mathrm{A} / \mathrm{PR} / 8 / 34)$ for $1 \mathrm{~h}$. Following infection, the medium was discarded and cells were washed with PBS three times. Next, MEM was added to the cells and incubation was carried out in a $\mathrm{CO}_{2}$ incubator at $37^{\circ} \mathrm{C}$, and $\mathrm{G} 2$ was added $1 \mathrm{~h}$ prior to infection, or at the same time as the virus, or $1,2,3,4,6$ or $8 \mathrm{~h}$ following infection. At $12 \mathrm{~h}$ following infection, the supernatants were collected and infectious titers were determined by plaque assay.

Activities against non-influenza viruses. The activities of G2 against RSV (21), ADV (22), PIV3 (23) and EV71 (24) were evaluated. A total of $100 \mathrm{TCID}_{50}(50 \%$ tissue culture infective dose) of the viral infective titer was allowed to adsorb 
A

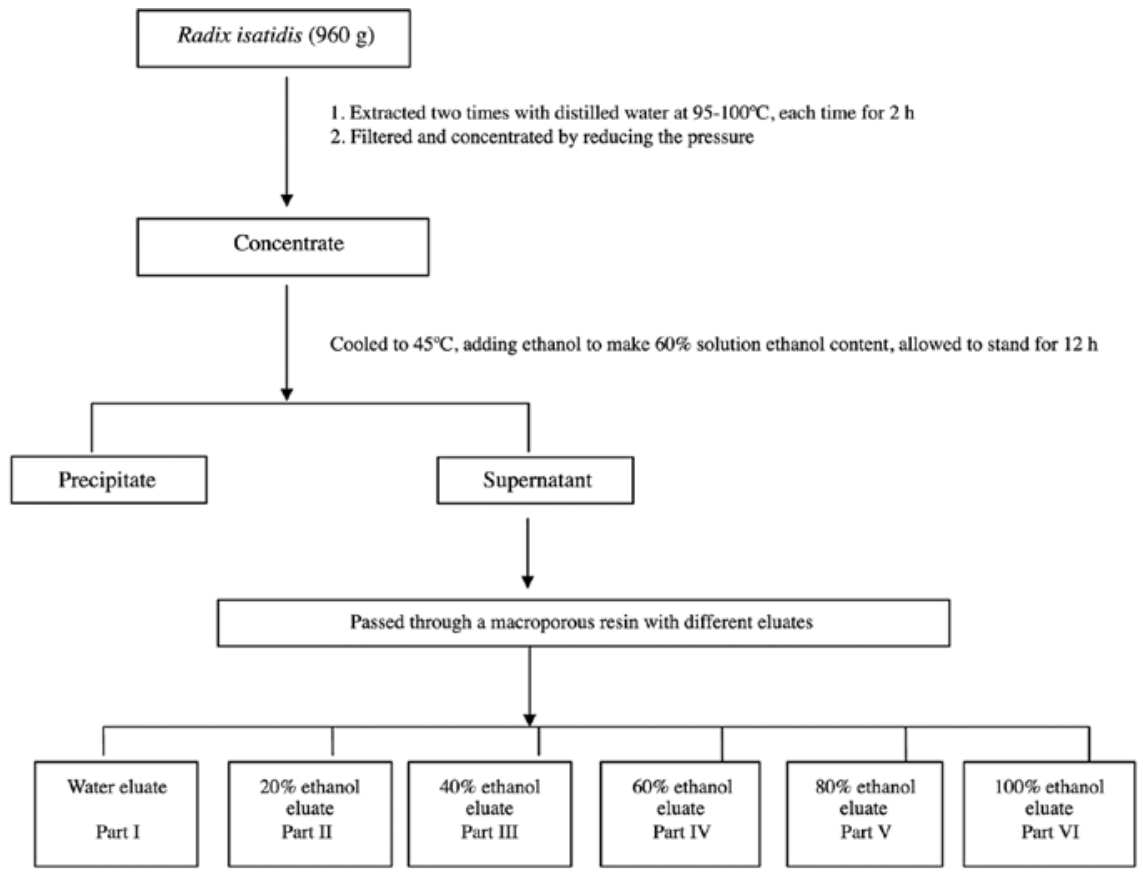

$\mathbf{B}$

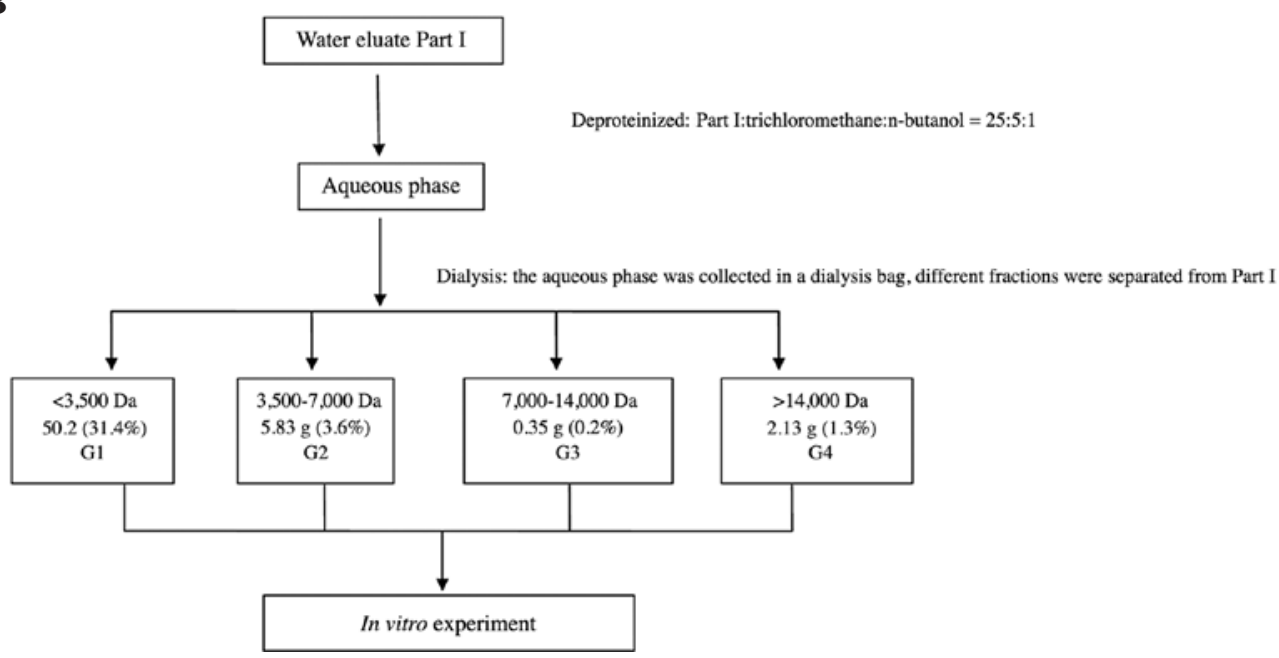

Figure 1. Extraction and purification protocol for G2 from Radix isatidi. (A) Preparation of the water eluate (Part I). (B) Isolation and purification of G2 by dialysis.

to the appropriate confluent cell lines for $1 \mathrm{~h}$, followed by washing of each virus with serum-free medium. Then the test medium containing the desired concentration of G2 was added. Following appropriate periods of incubation, the CPE in the virus-infected cells was observed microscopically, and the TCID $_{50}$ was determined by the method of Reed and Muench (25). The $\mathrm{IC}_{50}$ was determined as described previously (26).

Viral resistance. MDCK cells were infected with influenza A virus $(\mathrm{A} / \mathrm{FM} / 1 / 47)(\mathrm{MOI}=0.01)$ and left untreated, or treated with G2, amantadine (Sigma-Aldrich, St. Louis, MO, USA) or ribavirin for $24 \mathrm{~h}$. The post-infection supernatants were taken and used for infection in the second round of investigation. Following infection, cells were left untreated or treated with the indicated amount of G2 or amantadine again. This procedure was repeated six times. Supernatants were assayed for progeny virus yields by standard plaque titrations. Virus yields of mock-treated cells were arbitrarily set as $100 \%$ (17).

Statistical analysis. All experiments were carried out in triplicate and were representative of at least three separate experiments unless otherwise stated. Statistical significance of the data was determined by one-way ANOVA method using SPSS 12.0 software. $\mathrm{P}<0.05$ was considered to be statistically significant.

\section{Results}

Extraction and isolation of $G 2$. The protocol for extraction and purification of G2 from IIR is shown in Fig. 1. The results of the CPE activity assay showed that the water elute (part I) showed prominent activity (data not shown). Then, part I was deproteinized with Sevag reagent, dialyzed and lyophilized 
Table I. Inhibitory effects of different fractions of Isatis indigotica root extract on infection by influenza A virus (A/PR/8/34, H1N1).

\begin{tabular}{|c|c|c|c|c|c|c|c|c|}
\hline \multirow[t]{2}{*}{ Extracts } & \multirow[t]{2}{*}{ MW (Da) } & \multirow[t]{2}{*}{$\mathrm{TC}_{50}(\mathrm{mg} / \mathrm{ml})^{\mathrm{a}}$} & \multicolumn{2}{|c|}{ A } & \multicolumn{2}{|c|}{ B } & \multicolumn{2}{|c|}{$\mathrm{C}$} \\
\hline & & & $\mathrm{IC}_{50}{ }^{\mathrm{a}}$ & SI & $\mathrm{IC}_{50}^{\mathrm{a}}$ & SI & $\mathrm{IC}_{50}{ }^{\mathrm{a}}$ & SI \\
\hline G1 & $<3,500$ & 27.5 & $>10$ & $<1$ & 10 & $<1$ & $>10$ & $<1$ \\
\hline G2 & $3,500-7,000$ & 14.5 & $>10$ & $<1$ & 2.5 & 5.8 & 0.625 & 23.2 \\
\hline G3 & $7,000-14,000$ & 6.9 & $>10$ & $<1$ & $>10$ & $<1$ & $>10$ & $<1$ \\
\hline G4 & $>14,000$ & 10.0 & $>10$ & $<1$ & $>10$ & $<1$ & $>10$ & $<1$ \\
\hline
\end{tabular}

A, pretreatment prior to virus adsorption; B, treatment after virus adsorption; $\mathrm{C}$, drug and virus reaction prior to virus adsorption. ${ }^{\mathrm{a}}{ }^{\mathrm{M}} \mathrm{ean}$ values of results from two or three independent experiments. SI, selection index, $\mathrm{SI}=\mathrm{TC}_{50} / \mathrm{IC}_{50}$

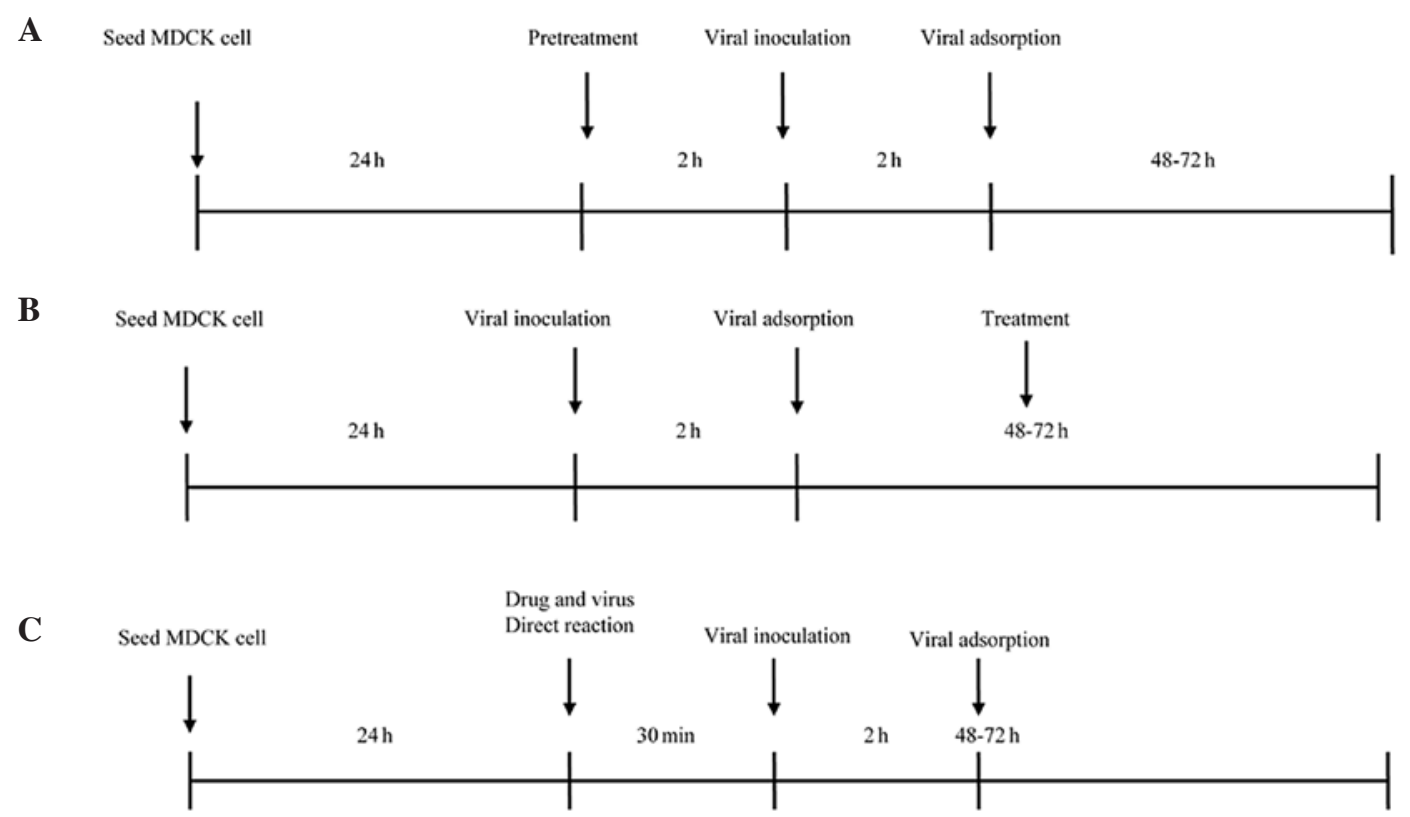

Figure 2. Three modes of treatment with G2. (A) Pretreatment prior to virus adsorption. (B) Treatment after virus adsorption. (C) Drug and virus reaction prior to virus adsorption.

to get four brown fraction mixtures: G1 $(<3,500 \mathrm{Da}), \mathrm{G} 2$ $(3,500-7,000 \mathrm{Da}), \mathrm{G} 3(7,000-14,000 \mathrm{Da})$ and G4 (>14,000 Da). The activity of G1-4 was assessed using a plaque assay and the results showed that G2 had marked activity (Table I).

Characterization of G2. Using the phenol-sulfuric acid method, with glucose as the standard solution, the total sugar content of G2 was 57.7\%; using the Bradford method, with bovine serum albumin as the standard, the total protein content was $1.8 \%$. The other constituents were not detected (data not shown).

Cytotoxicity. G2 was tested for cytotoxicity against MDCK, HEp-2 and LLC-MK2 cells. The MTT data indicated that G2 did not negatively affect the viability of cells (data not shown).

Anti-influenza activity of G2. G2 was tested using a plaque assay for inhibition against a series of human and avian influenza viruses at various magnitudes of activity. As shown in Table II, the mode of action of G2 was studied. When MDCK cell lines were pretreated with G2 followed by infection with influenza virus, no protective effect was observed. However, when MDCK cell lines were treated with G2 following virus incubation, virus titer decreased in comparison to the medium-treated control. In particular, when influenza viruses $(\mathrm{MOI}=0.01)$ were pre-incubated with $\mathrm{G} 2$ for $30 \mathrm{~min}$ prior to infection, a pronounced titer reduction in progeny virus was detected. These results indicated that G2 may display anti-influenza virus activity by preventing viral attachment.

Anti-hemagglutination activity of pretreated virus particles. To further investigate whether G2 prevents the attachment of virus particles to cell surface receptors, a hemagglutination inhibition (HAI) assay was performed, as G2 was not able to attach to guinea pig erythrocytes by itself.

$\mathrm{G} 2$ pre-incubation with the viruses prevented the binding of various viruses to red blood cells in this assay (Fig. 3), 
Table II. In vitro anti-influenza virus activities of $\mathrm{G} 2$, amantadine and ribavirin.

\begin{tabular}{lcccc}
\hline Virus type and strain & \multicolumn{3}{c}{$\mathrm{IC}_{50}(\mathrm{mg} / \mathrm{ml})^{\mathrm{a}}$} \\
\cline { 2 - 5 } & $\mathrm{G} 2^{\mathrm{b}}$ & $\mathrm{G}^{\mathrm{c}}$ & Amantadine $^{\mathrm{b}}$ & Ribavirin $^{\mathrm{b}}$ \\
\hline A/PR/8/34 (H1N1) & 1 & 0.39 & $>0.05$ & 0.0370 \\
A/FM/1/47 (H1N1) & 10 & 4.14 & 0.017 & 0.0068 \\
A/Guangzhou/GIRD07/09 (H1N1) & $>10$ & 4.30 & $>0.05$ & 0.0120 \\
A/Guangzhou/GIRD02/2009 (H1N1) & 7.64 & 0.95 & 0.05 & 0.0130 \\
A/Aichi/2/68 (H3N2) & 8.53 & 2.85 & 0.015 & 0.0210 \\
A/Duck/Guangdong/2009 (H6N2) & $\mathrm{NT}$ & 5.00 & 0.025 & 0.0090 \\
A/Duck/Guangdong/1994 (H7N3) & $\mathrm{NT}$ & 3.96 & $>0.05$ & 0.0140 \\
A/Chicken/Guangdong/1996 (H9N2) & $\mathrm{NT}$ & 3.91 & $>0.05$ & 0.0210 \\
B/Guangzhou/GIRD08/09 & $\mathrm{NT}$ & 3.63 & 0.0210
\end{tabular}

${ }^{a}$ Mean values of results from two or three independent experiments. ${ }^{b}$ Treatment following virus adsorption. ${ }^{c}$ Drug and virus reaction prior to virus adsorption. NT, not tested.

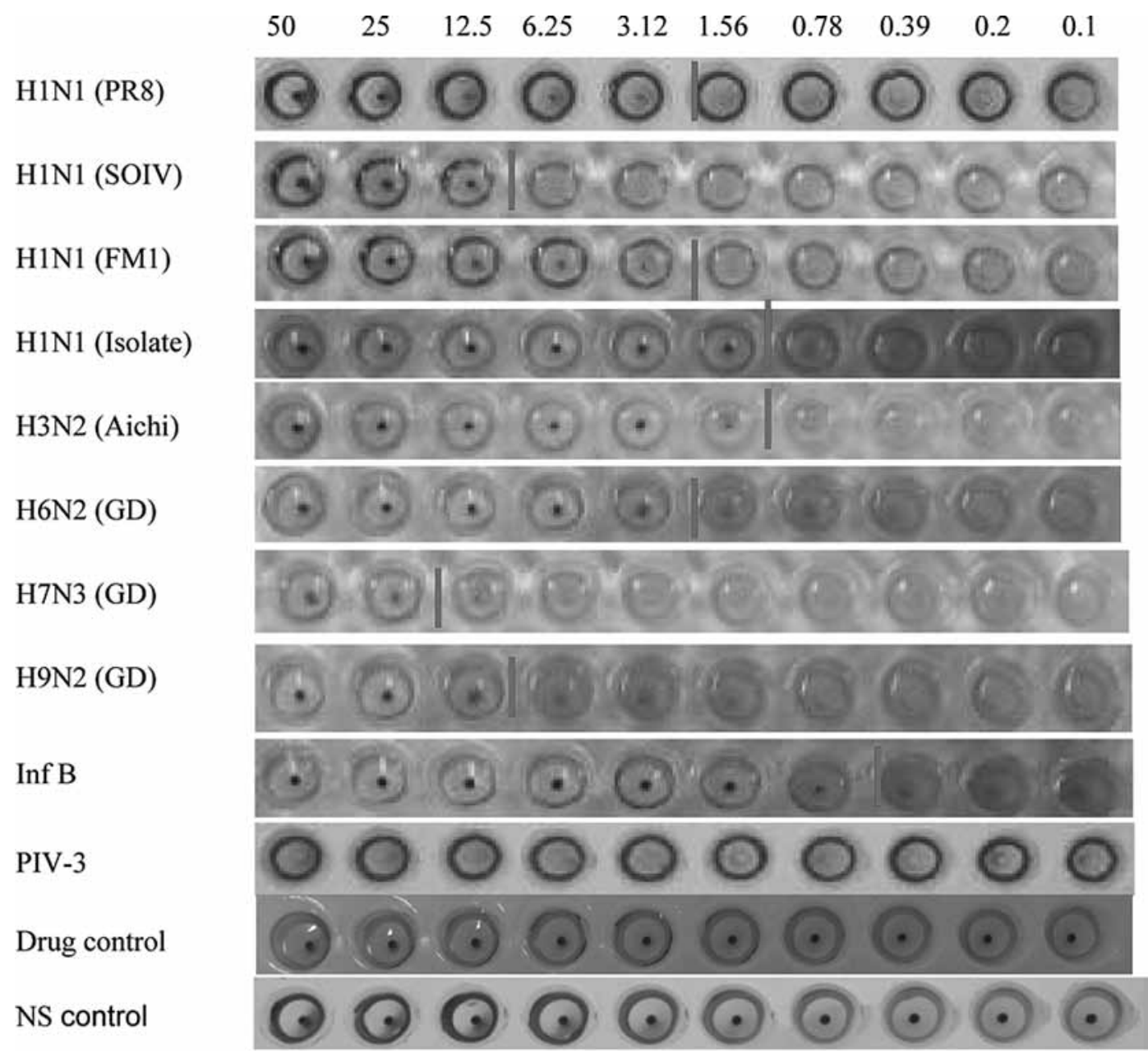

Figure 3. G2 inhibits hemagglutination activity of influenza viruses and inhibits replication of influenza viruses. G2 was serially diluted as indicated and virus stocks (4 HA/well) were dissolved in normal saline (NS) and $50 \mu 1$ was added per well of a 96-well plate. After pre-incubation for 60 min, $0.5 \%$ guinea pig erythrocytes were mixed with the solution. In the samples where viruses were pre-incubated with G2, viral particles were no longer capable of agglutinating erythrocytes at a specific dilution, indicating an interaction of $\mathrm{G} 2$ with the viral HA. (Concentration unit of $\mathrm{G} 2, \mathrm{mg} / \mathrm{ml})$.

which indicates that G2 may be capable of directly interfering with the binding between viral hemagglutinin and cell receptors. Moreover, G2 cannot interfere with the HN of parainfluenza 3 virus. Hence, G2 probably acts as a specific disruptor of viral hemagglutinin attachment to the host cell surface. 


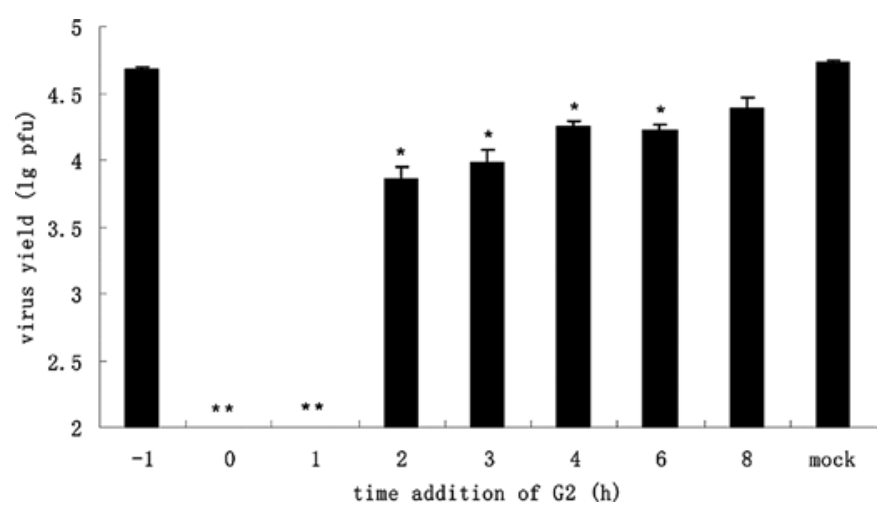

Figure 4. Effect of time of addition of $\mathrm{G} 2$ on the influenza virus yield in MDCK cells. MDCK cells were infected with virus (A/PR/8/34, MOI=0.01) for $1 \mathrm{~h}$. Following infection, the medium was discarded and cells were washed with PBS. MEM was then added to the cells and incubated in a $\mathrm{CO}_{2}$ incubator at $37^{\circ} \mathrm{C}$. G2 was added $1 \mathrm{~h}$ prior to infection and then again at $0,1,2,3,4,5,6$ and $8 \mathrm{~h}$ following infection. At $12 \mathrm{~h}$ following infection, the supernatants were collected and infectious titers were determined by a plaque assay. The mean difference was statistically significant. "p $<0.05$, *** $<0.01$.

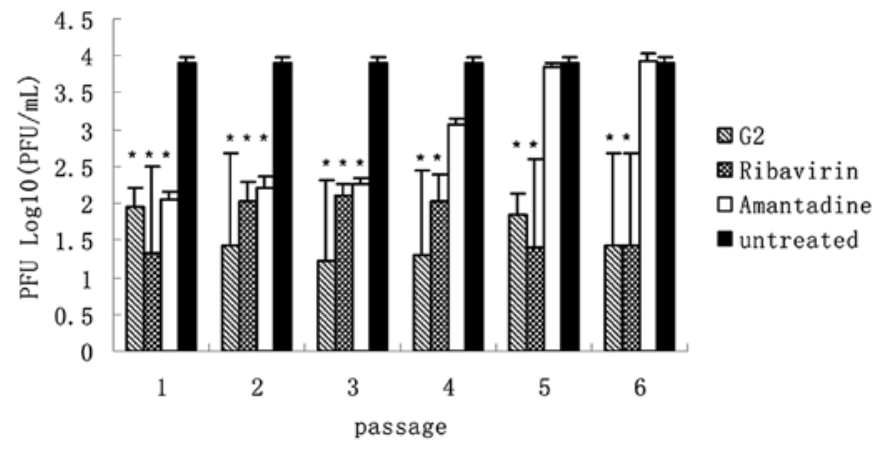

Figure 5. Susceptibility of influenza A virus with increasing passage of virus in MDCK cells exposed to inhibitors. MDCK cells were infected with influenza A virus $(\mathrm{A} / \mathrm{FM} / 1 / 47, \mathrm{MOI}=0.01)$ and were left untreated or treated with the drugs $(\mathrm{G} 2,1 \mathrm{mg} / \mathrm{ml}$; ribavirin, $0.03 \mathrm{mg} / \mathrm{ml}$; amantadine, $0.03 \mathrm{mg} /$ $\mathrm{ml})$. At $48 \mathrm{~h}$ post-infection, supernatants were removed and MCDK cells were infected for the second time. Following infection, the cells were left untreated or treated with the drugs. This procedure was repeated six times. The supernatants were assayed for progeny virus by plaque titration. The mean difference was significant, ${ }^{*} \mathrm{p}<0.05$.

Time of addition of the G2. Influenza virus A/PR/8/34 (H1N1) was tested, and pre-incubation of cells with G2 followed by virus infection showed no virus reduction. When cells were infected first and exposed to G2 (Fig. 4), virus replication was greatly inhibited. There are no bars in the 0 and $1 \mathrm{~h}$ due to these data being below the detection limit.

Spectrum of anti-viral activity. The spectrum of anti-viral activity of G2 was investigated. It did not inhibit the CPE caused by RSV, ADV, PIV3 and EV71, as the $\mathrm{IC}_{50}$ in all cases was greater than $10 \mathrm{mg} / \mathrm{ml}$ (data not shown).

Tendency to induce viral resistance. As the drug acts on the M2 ion channel or neuraminidase, mutations of amino acid residues in viral proteins may cause drug resistance. However, the virus should not easily overcome the inhibitory effect of amino acid mutations in viral surface proteins. Therefore, a multi-passaging experiment to detect the emergence of resistant viruses in cell culture was set up as a reference (27). As shown in Fig. 5, virus titers from cells treated with amantadine were at the same levels as untreated cells following five passages, showing that this pool of viruses had become fully resistant to the drug. This was different for infected cells treated with G2, where viral titers did not rise with increasing passage numbers, indicating that the influenza virus was not resistant to G2.

\section{Discussion}

In this study, we obtained a crude extract, G2, which was isolated from IIR by hot water extraction, ethanol precipitation and dialysis. The G2 extract had a molecular weight range from 3,500-7,000 Da and showed an inhibitory effect on various human and avian influenza viruses in vitro without producing any significant toxicity. Although G2 inhibited the replication of human and avian viruses, the activity appeared more prominent against human influenza viruses than avian influenza viruses, which may be attributed to the conformational differences of hemagglutinin.

To determine how G2 acts on the viral life cycle, the mode of action was also investigated. Pretreatment of cells with G2 had little effect on influenza infectivity. Treatment following infection with G2 had an inhibitory effect on plaque reduction of the human or avian influenza viruses tested (data not shown). A significant virus titer decrease was also detected when cells were infected with virus preparations pre-incubated with G2. The inhibitory activity of G2 against hemagglutinin was assessed using an HAI. G2 pretreatment prevented binding of various influenza viruses to red blood cells in this assay, indicating that G2 is capable of directly interfering with the viral hemagglutinin in a dose-dependent manner. Additionally, G2 inhibited virus replication when added between 0 and $6 \mathrm{~h}$, particularly $0-1 \mathrm{~h}$ following infection; pretreatment of cells, or addition at later stages of viral infection did not affect virus replication. Taken together, our results suggested that G2 may interfere with the virus surface proteins and inhibit binding of virus particles to cellular receptors.

Further support for a specific interaction between G2 and influenza viruses came from the observation that $\mathrm{G} 2$ was active against influenza A and B viruses, but not against non-influenza viruses (RSV, PIV3, ADV and EV71) suggesting that the mode of action of $\mathrm{G} 2$ acts by distinct mechanisms depending on the virus. G2 did not interfere with parainfluenza virus attachment to cells, in contrast to the data regarding influenza viruses. Our results demonstrated that G2 inhibited influenza virus attachment to cells, leading to decreased viral replication. Thus, the primary antiviral mechanism was inhibiting viral attachment.

Taken together, G2 has certain advantages as follows. First, it is derived from extracts of IIR, which has been used for thousands of years in China to treat influenza-like illnesses effectively. Second, this novel extract also has inhibitory effects on amantadine-resistant strains of influenza viruses, suggesting that its antiviral activity may involve a different mode of action from current agents. Third, G2 treatment may not easily result in the emergence of virus drug resistance compared with M2 inhibitors. 
Furthermore, the base of traditional Chinese medicine consists of active agent groups, which play a role in multitargeting, displaying a multiple effect. Thus, the antiviral activity was a combined action of different effective and functional components. G2 is a crude extract from IIR with the known component being total sugar $(57.7 \%$ ) (protein $1.8 \%$ ), but it may consist of another constituent, which has not yet been detected, and thus G2 may exhibit combined antiviral activities. Therefore, to define the active composition, further fractionation and analysis of $\mathrm{G} 2$ is required.

Given its inhibitory effects against influenza viruses and that the probable mechanism of action differs from current antiviral agents, G2 is considered to be a satisfactory candidate as an anti-influenza drug. Nevertheless, it appears to be a promising option as a replacement or supplementary strategy to currently available anti-influenza agents. Additional studies are underway to further define the anti-influenza virus effects in vivo and its active components.

\section{Acknowledgements}

We thank Hutchison Whampoa Guangzhou Baiyunshan for providing the drugs and funding for this study. The study was also partly supported by grants from The Science and Technology Development Fund in Macao S.A.R. (grant no. 043/2007/A3), the Joint Research Foundation of Department of Education, Guangdong Province (grant no. gxzd0901), Recruitment Project of Guangzhou Technology Bureau for enterprises scientific and technological problems (Grant no. 2008Z1-I011). We would also like to thank Professor Jiang Zhihong, Dr Lee Ming Yuan and Dr Chen Jingxian for the discussions and reviewing during the course of the work, as well as Lin Qing and Li Runfeng for the technical support.

\section{References}

1. Kuszewski K and Brydak L: The epidemiology and history of influenza. Biomed Pharmacother 54: 188-195, 2000.

2. Laver G and Garman E: Pandemic influenza: its origin and control. Microbes Infect 4: 1309-1316, 2002.

3. Dawood FS, Jain S, Finelli L, et al: Emergence of a novel swineorigin influenza A (H1N1) virus in humans. N Engl J Med 360: 2605-2615, 2009.

4. Beigel $\mathbf{J}$ and Bray M: Current and future antiviral therapy of severe seasonal and avian influenza. Antiviral Res 78: 91-102, 2008.

5. Chan PK: Outbreak of aviar influenza A(N5H1) virus infection in Hong Kong in 1997. Clin Infect Dis 34 (Suuppl 2): S58-S64, 2002.

6. Chang YS and Ho YL: Studies on the Homonymic Chinese Crude Drug Species in Taiwan evaluation of the quality of DA-Ching-Yeh and Ching-Dai. Anal Sci 17: a423-426, 2001.
7. Wu XY, Liu YH, Sheng WY, Sun J and Qin GW: Chemical constituents of Isatis indigotica. Planta Med 63: 55-57, 1997.

8. Liu YH, Qin GW and Ding SP: Studies on chemical constituents from root of Isatis indigotica (I). Chin Trad Herb Drugs 32: 1057-1060, 2001.

9. Liu YH, Qin GW and Ding SP: Studies on chemical constituents from root of Isatis indigotica (III). Chin Trad Herb Drugs 33: 97-99, 2002.

10. Liu YH, Wu XY and Fang JG: Studies on chemical constituents from Radix isatidis. Herald Med 22: 591-593, 2003.

11. Ding SP, Liu YH and Li J: Study of the chemical constituents of Isatis Fort. (Cruciferea). Herald Med 20: 475-476, 2001.

12. Fang GR, Hu JH, Li BH, Zhang HM, Lin $\mathrm{H}$ and An DK: Separation and analysis of five organic acids in autotetraploid Radix isatidis by capillary electrophoresis. J Chin Pharm Univ 31: 111-114, 2000

13. Mak NK, Leung CY, Wei XY, Shen XL, Wong RN, Leung KN and Fung MC: Inhibition of RANTES expression by indirubin in influenza virus-infected human bronchial epithelial cells. Biochem Pharmacol 67: 167-174, 2004.

14. Yamada H: Antiviral compositions containing new glycoprotein from Isatis tinctoria. [P].JP:1160, 599 [9960,599], 1999-03-02.

15. Chaplin MF and Kennedy JF: Carbohydrate Analysis. 2nd edition. Oxford University Press, New York, NY, 1994.

16. Bradford MM: A rapid and sensitive method for the quantitation of microgram quantities of protein utilizing the principle of protein-dye binding. Anal Biochem 72: 248-254, 1976.

17. Ehrhardt C, Hrincius ER, Korte V, et al: Polyphenol rich plant extract, CYSTUS052, exerts anti-influenza virus activity in cell culture without toxic side effects or the tendency to induce viral resistance. Antiviral Res 76: 38-47, 2007.

18. Yingsakmongkon S, Miyamoto D, Sriwilaijaroen $\mathrm{N}$, et al: In vitro inhibition of human influenza A virus infection by fruit-juice concentrate of Japanese plum (Prunus mume SIEB. et ZUCC). Biol Pharm Bull 31: 511-515, 2008.

19. Miyamoto D, Hasegawa S, Sriwilaijaroen N, et al: Clarithromycin inhibits progeny virus production from human influenza virus-infected host cells. Biol Pharm Bull 31: 217-222, 2008.

20. Knox YM, Suzutani T, Yosida I and Azuma M: Anti-influenza virus activity of crude extract of Ribes nigrum L. Phytother Res 17: 120-122, 2003.

21. Graham BS, Perkins MD, Wright PF and Karzon DT: Primary respiratory syncytial virus infection in mice. J Med Virol 26: $153-162,1988$

22. Hui MB, Lien EJ and Trousdale MD: Inhibition of human adenoviruses by 1-(2'-hydroxy-5'-methoxybenzylidene)amino3-hydroxyguanidine tosylate. Antiviral Res 24: 261-273, 1994.

23. Mao H, Thakur CS, Chattopadhyay S, Silverman RH, Gudkov A and Banerjee AK: Inhibition of human parainfluenza virus type 3 infection by novel small molecules. Antiviral Res 77: 83-94, 2008.

24. Hung YH, Cheng ML, Weng SF, Leu YL and Chiu DT: Antiviral effect of epigallocatechin gallate on enterovirus 71. J Agric Food Chem 57: 6140-6147, 2009.

25. Reed LJ and Muench H: A simple method of estimating fifty percent endpoints. Am J Hyg 27: 493-497, 1938.

26. Ludwig S, Wolff $\mathrm{T}$ and Ehrhardt $\mathrm{C}$ : MEK inhibition impairs influenza B virus propagation without emergence of resistant variants. FEBS Lett 561: 37-43, 2004

27. Taubenberger JK: The origin and virulence of the 1918 'Spanish' influenza virus. Proc Am Philos Soc 150: 86-112, 2006. 